\title{
Psicologia Fenomenológica, Psicanálise existencial e possibilidades clínicas a partir de Sartre
}

\section{Phenomenological psychology, existential psychoanalysis and clinical possibilities from Sartre}

\author{
André Barata Nascimento* \\ Universidade da Beira Interior - UBI - Covilhã, Lisboa, Portugal
}

\section{Carolina Mendes Campos**}

Pontifícia Universidade Católica do Rio de Janeiro - PUC-Rio, Rio de Janeiro, Rio de Janeiro, Brasil

\author{
Fernanda Alt $* * *$ \\ Universidade do Estado do Rio de Janeiro - UERJ - Rio de Janeiro, Rio de Janeiro, \\ Brasil
}

\begin{abstract}
RESUMO
Esse artigo visa clarificar o âmbito preciso em que se constituem três campos distintos de consideração do pensamento de Sartre para o universo da psicologia. Em primeiro lugar, o campo de uma psicologia fenomenológica sartriana, particularmente aprofundado na fase inicial das investigações fenomenológicas de Sartre. Em segundo lugar, o campo de uma proposta de psicanálise existencial como alternativa e resposta à psicanálise freudiana. Por fim, as possibilidades de uma clínica inspirada no pensamento de Sartre. É crucial levar a cabo estas demarcações, ultrapassando incompreensões, e encorajando uma atitude cuidadosa, dialogante, sobretudo na busca por obter consequências para a ideia de uma prática clínica inspirada em Sartre. Com efeito, esta prática clínica a partir de uma perspectiva sartriana só pode ser constituída através da exploração heurística, no relacionamento entre descoberta e invenção, dos legados que Sartre deixou na forma de uma psicologia fenomenológica original e de uma psicanálise existencial.
\end{abstract}

Palavras-chave: fenomenologia, psicologia, psicanálise, clínica, Sartre.

\begin{abstract}
This paper aims to clarify the precise scope in which three distinct fields of consideration of Sartre's thought, to the world of psychology, are constituted. Firstly, the field of a Sartrean phenomenological psychology, particularly extended in the initial phenomenological investigations of Sartre. Second, the scope of a scheme for an existential psychoanalysis as an alternative and a response to Freudian psychoanalysis. Finally, the idea of a clinical practice inspired by Sartre's thought. It is critical to carry out these boundaries, overcoming misunderstandings, and encourage a caring and dialoguing attitude, especially with regard to aimed consequences to the idea of a clinical practice inspired on Sartre. In fact, this clinical practice from a sartrean perspective can only be build up based on the heuristic
\end{abstract}


exploration, by the relationship between discovery and invention, of the legacies that Sartre has left in the form of an original phenomenological psychology and of an existential psychoanalysis.

Keywords: phenomenology, psychology, psychoanalysis, clinic, Sartre.

\section{Introdução}

Esse trabalho se propõe a estabelecer uma organização a respeito de três campos distintos que ligam o pensamento de Jean-Paul Sartre à psicologia, a saber, a psicologia fenomenológica, a psicanálise existencial e as possibilidades para uma clínica. Mais ainda, pretendemos clarificar o âmbito preciso no qual cada um desses três campos se constituem no interior da obra sartriana. Para isso, iremos discutir questões diretamente abordadas pelo autor, assim como questões apenas indicadas pelo mesmo, que apontam na direção de um caminho ainda por se fazer, isto é, desenvolvimentos possíveis a partir da obra de Sartre. Em primeiro lugar, vamos apontar brevemente as bases husserlianas que permitem a Sartre desenvolver sua própria psicologia fenomenológica, aprofundada, sobretudo, em seus estudos e publicações dos anos 30. Do mesmo modo, iremos elencar os principais desdobramentos obtidos por Sartre a partir de tais investigacões. Em segundo lugar, discutiremos o campo sartriano de uma proposta de psicanálise existencial como alternativa e resposta à psicanálise freudiana. Finalmente, faremos algumas reflexões sobre as possibilidades de uma clínica inspirada no pensamento de Sartre. Acreditamos que esse percurso aqui desenhado pode servir como norteador para estudantes e profissionais que desejem se aproximar da obra sartriana e pensar outras perspectivas para um trabalho clínico.

\section{Psicologia Fenomenológica: a formação de um campo}

Em seu artigo sobre fenomenologia para a Enciclopédia Britannica datado de 1927, Husserl (2001), logo de início, estabelece uma diferenciação do trabalho fenomenológico em dois planos de investigação. De um lado, uma fenomenologia transcendental, claramente dirigida às estruturas últimas da consciência que uma investigação fenomenológica consegue alcançar através dos seus recursos próprios - époché, reflexão, variação eidética, intuição e descrição; do outro, o campo de uma psicologia fenomenológica dirigida à multiplicidade das vivências intencionais com o intuito de as apreender diferenciadamente no seu significado essencial.

Se a fenomenologia transcendental se propõe a reformar a filosofia no sentido da sua transformação em uma ciência de rigor ou, ao 
menos, como base para todas as outras ciências, já a psicologia fenomenológica, visa constituir uma psicologia, metodologicamente bem fundada, que proporcione uma compreensão em profundidade da vida psicológica do humano. Por exemplo: obter a elucidação concreta da essência de vivências intencionais particulares, tais como a de emoções, ou um tipo de consciência intencional como a consciência imaginante.

Nos seus primeiros textos filosóficos, Sartre não só se mostra perfeitamente conhecedor desta distinção entre uma fenomenologia transcendental e uma psicologia fenomenológica, como acrescenta, enquanto intérprete do pensamento do fenomenólogo alemão, que esta psicologia não é incompatível com uma psicologia da experiência. Lê-se por exemplo em A Imaginação:

Ele [Husserl] não nega que haja uma psicologia da experiência, mas pensa que, para atender ao mais urgente, o psicólogo deve constituir antes de tudo uma psicologia eidética. [...] será uma "psicologia fenomenológica": ela fará, no plano intramundano, pesquisas e fixações de essências como as da fenomenologia no plano transcendental. (SARTRE, 2008, p.122)

É facilmente demonstrável que grande parte do esforço de Sartre nas suas obras iniciais vai na direção não de uma fenomenologia transcendental, mas da tal psicologia fenomenológica que Husserl constituíra como ciência fenomenológica. Isto é inteiramente claro quer em A Imaginação (1936), O Imaginário (1940), Esboço para uma teoria das emoções (1939) e A Transcendência do Ego (1936), todas elas obras que refletem a preocupação de Sartre em demarcar, seja quanto objeto, seja quanto ao método, o âmbito preciso de uma psicologia fenomenológica. A dispersão de títulos terá, pelo menos em parte, relação com a desistência de Sartre em concluir um livro que se intitularia justamente $A$ Psique.

Os enunciados metodológicos sobre esta ciência podem ser vistos por exemplo em A Imaginação:

[...] O método da fenomenologia pode servir de modelo aos psicólogos. Certamente, o procedimento essencial desse método continua sendo a "redução", a epoché, ou seja, a colocação entre parênteses da atitude natural; e está bem entendido que o psicólogo não efetua essa epoché e permanece no terreno da atitude natural. Contudo, feita a redução, o fenomenólogo tem meios de pesquisa que poderão servir ao psicólogo: a fenomenologia é uma descrição das estruturas da consciência transcendental fundada na intuição das essências dessas estruturas. Naturalmente, esta descrição opera-se no plano da reflexão. (SARTRE, 2008, p.119-120) 
A psicologia fenomenológica implica a suspensão, por decisão metodológica, da atitude natural, assim posta entre parênteses. E procede por reflexão, colocando portanto a consciência como tema de si mesma, consciência refletida posicionada pela consciência reflexiva, sem, contudo, haver entre elas coincidência.

Por sua vez, em A Transcendência do Ego, diversas considerações metodológicas são feitas no mesmo sentido, sublinhando o caráter reflexivo da psicologia fenomenológica, assentada em descrições de fatos fenomenológicos - o que Sartre chama de uma ciência de fato e não em considerações que relevassem de uma filosofia crítica, ao estilo kantiano ou neokantiano (SARTRE, 1994).

\section{Elementos para uma Psicologia Fenomenológica Sartriana}

Acreditamos que não será impróprio denominar como psicologia sartriana os resultados que Sartre adquire em sua investigação psicológica de carácter fenomenológico. Admitindo então uma psicologia sartriana nestes termos, há um conjunto de enunciados de considerável originalidade que the podem ser imputados.

\subsection{Emoções}

O mundo apresenta-se à consciência como obstáculos e dificuldades a serem transpostos, que envolvem sempre algum coeficiente de adversidade. As emoções introduzem nestas relações um elemento de modulação nas significações com que os objetos mundanos se apresentam a uma consciência, "temperando" a adversidade. Sartre fornece um exemplo muito simples desta plasticidade: quando a percepção de que um cacho de uvas não está afinal ao alcance da mão, a consciência transforma a sua relação com o mundo emocionalmente. O cacho de uvas torna-se irrefletidamente menos atraente - agora, cacho de uvas verdes -, resultando que a adversidade do mundo fica, assim, amenizada pelo desinvestimento emocional (SARTRE, 2007). Outros exemplos: uma emoção como a alegria é uma antecipação do gozo que as distâncias e as adversidades superadas adiante virão a proporcionar, e a tristeza traduz uma relação inibida com o mundo, inibindo, com isso, adversidades que se adivinham frustrantes. Esta modulação plástica altera não tanto o mundo, na sua objetiva adversidade, mas a maneira como o vivemos. Contudo, não sendo possível isolar uma significação do mundo da referência à sua vivência, tal como não é possível falar de uma adversidade do mundo a não ser por referência a quem a sofra, na verdade a vida emocional, segundo Sartre (2007), introduz um ingrediente de magia nas relações com os objetos do mundo. 


\subsection{Imaginação}

Como a emoção, também a imaginação é uma relação com o mundo, mas uma relação pela qual a consciência faz aparecer, sobre um mundo que nega, e, portanto, sobre a sua adversidade e resistência, irrealidades imaginadas. $\mathrm{Na}$ sua efetiva ausência, ou mesmo inexistência, nada prende as imagens da imaginação ao mundo, ainda que, como bem nota Sartre, nada nelas seja original, tudo nelas é oriundo do "já conhecido", revelando na verdade uma pobreza intrínseca que nada dá a conhecer. A sua função é outra, bem mais próxima da função da emoção, com que tende a cooperar. Por exemplo, a emoção de alegria pode fazer-se acompanhar pela imagem da fonte dessa alegria, ou a emoção da cólera pela imagem de quem encoleriza.

\subsection{Estados}

A fina análise de Sartre dá conta que "estados" como o do ódio ou o do amor só se constituem através da reflexão e de uma forma dubitável, bem diversamente das emoções, como a de atração ou a de repulsa. Por exemplo, posso ser consciência de repulsa e da cólera por Pedro e, no entanto, não estar certo de que o odeie. A imediatez emocional da repulsa e da cólera não se estende ao "estado" de ódio. Com efeito, acrescenta Sartre, o ódio é, então, objeto transcendente que me aparace através da experiência irrefletida de repulsa (SARTRE, 1994). Os estados, de que o amor e o ódio constituem exemplo, são objetos transcendentes para a consciência, revelandose, por isso, de uma perspectiva de conhecimento, como realidades falíveis, e ainda, de uma perspectiva existencial, como realidades inertes, incapazes de qualquer determinação da vida da consciência.

\subsection{Qualidades}

Da mesma maneira que os estados se constituem reflexivamente como se fossem a disposição psíquica de que emanariam as emoções - "sinto repulsa porque o odeio", por exemplo -, ou para usar uma terminologia mais técnica, unidade noemática de espontaneidades, as qualidades se constituiríam, por seu turno, como substratos daqueles estados, como potencialidades de que os estados seriam atualização. - "Amo porque tenho a qualidade ou defeito de ser uma pessoa apaixonada", por exemplo.

\subsection{Ego}

A vida espontânea da consciência irrefletida seria, por laço mágico, emanação de estados psíquicos, que, por seu turno, seriam atualizações de potencialidades, a que Sartre chama qualidades, e que, na unidade sintética desta pluralidade de objetos transcendentes à consciência, vale como Ego de uma consciência. Toda esta projeção só sucede no momento em que a consciência se desdobra em 
reflexão, o que significa que, enquanto tal não sucede, ou seja, enquanto permanecemos no plano da consciência irrefletida, não temos a experiência do Ego; na verdade, nem sequer temos um Ego aí, que permanecesse, porém, inapercebido. Na vida irrefletida da consciência fica evidenciada a ausência de papel do Ego pela sua ausência em absoluto. Diz Sartre (1994): "O Ego aparece à reflexão como um objecto transcendente, que realiza a síntese permanente do psíquico" (p.65). Talvez não seja excessivamente arrojado reconhecer nesta transcendência que, no entanto, unifica, em uma instância totalmente externa à consciência, a vida psíquica humana, função similar ao estádio do espelho em Lacan e que, curiosamente, é apresentada no mesmo ano em que Sartre publica quer $A$ Transcendência do Ego quer A Imaginação. É, com efeito, em 1936, no Congresso internacional de psicanálise de Marienbad que Lacan, suportado em evidência empírica (oriunda da psicologia da infância e da etologia), expõe e interpreta a reação distintiva que as crianças manifestam quando postas diante da sua própria imagem refletida num espelho.

Laplanche e Pontalis resumem a noção de estádio do espelho da seguinte forma:

\begin{abstract}
Segundo Jacques Lacan, fase da constituição do ser humano, que se situa entre os 6 e os 18 primeiros meses; a criança, ainda num estado de impotência e falta de coordenação motora, antecipa imaginariamente a apreensão e o domínio da sua unidade corporal. Esta unificação imaginária opera-se por identificação com a imagem do semelhante como forma total; ela é ilustrada e actualizada pela experiência concreta em que a criança percebe a sua própria imagem num espelho. O estádio do espelho constituiria a matriz e o esboço do que será o eu (LAPLANCHE \& PONTALIS, 1992, p. 176-177).
\end{abstract}

Observe-se, porém, que Lacan e Sartre não dizem exatamente o mesmo. Antes seria o caso de o entendimento lacaniano de "moi" e o de Sartre convergirem ao entenderem ambos o eu como unidade transcendente da vida psíquica, unidade na verdade constituída e apenas aparentemente constituinte da consciência. É claro que Lacan vai bem mais longe na sua caracterização do estádio do espelho, até pelo recurso que faz a informação empírica, mas não pensamos errar se afirmarmos que o estádio do espelho de Lacan corrobora claramente o entendimento sartriano do ego.

\title{
3.6 Vida Psíquica
}

Os cinco pontos enumerados atrás expõem um quadro geral da vida psíquica fortemente marcada pelo que poderíamos designar externalismo sartriano. Não há um "dentro" ou "interior" da consciência, ela é inteiramente o seu exterior, e lhes são tão 
transcendentes os traços do seu mundo como os do seu Ego, jogando-se sempre "fora" de si a significação da sua vida consciente. E é, portanto, nas coisas aí fora que as significações aparecem. É nas coisas, nas próprias coisas, que uma consciência encontra a sua vida emocional.

\section{Psicanálise Existencial: o método}

Diante do panorama sobre aquilo que poderíamos entender como o desenvolvimento de uma psicologia fenomenológica nas mãos de Sartre, podemos observar, então, que esta só se distingue da husserliana no plano dos resultados que obtém e não tanto no plano da circunscrição da psicologia fenomenológica enquanto ciência. É claro nas referências que fizemos anteriormente, designadamente em A Transcendência do Ego e em O Imaginário, que Sartre adota, sem reservas, o método fenomenológico de Husserl, procurando empregar as indicações que este prescrevia, diferenciando atitude natural e atitude fenomenológica, recorrendo ao gesto intelectual da epoché, assumindo a intuição de essências como objetivo a alcançar, após um procedimento rigoroso, de reflexão, explicitação e descrição. Podemos, então, dizer que não é quanto ao seu método que encontramos alguma originalidade, pelo menos face a Husserl, na psicologia fenomenológica de Sartre. É sim, como pudemos observar, nos seus resultados, desde o início, claramente distintos dos de Husserl em pelo menos dois aspectos. Primeiramente, um entendimento diferente a respeito da intencionalidade da consciência - se para Husserl a intencionalidade é tomada como essencial à consciência, para Sartre, e por uma radicalização manifesta, a intencionalidade revela-se afinal como tudo o que a consciência pode ser, ou seja, seu único modo de ser. Em segundo lugar, mas em clara articulação com esta primeira diferença, um entendimento divergente sobre o papel e o lugar do Ego na relação com a consciência - para Sartre, ao contrário de Husserl, a nenhum nível, e de maneira nenhuma, tem cabimento considerar uma imanência do Ego à consciência. Em suma, se faz sentido falar de uma psicologia fenomenológica especificamente sartriana será apenas no plano dos seus resultados e nunca no plano da sua constituição como ciência, aspecto em que realmente se coloca numa posição de quem subscreve positivamente o método proposto por Husserl para uma psicologia fenomenológica.

Cabe indagar, em seguida, se este tipo de distinções que acabamos de fazer para a psicologia fenomenológica também é pertinente quando deslocamos a atenção para a psicanálise existencial. Pelo menos uma boa razão justifica a pergunta. Da mesma maneira que a psicologia sartriana se apresenta como um desenvolvimento, ainda 
que parcialmente divergente, de uma psicologia fenomenológica constituída como disciplina por outro autor, Husserl, também a psicanálise existencial se apresenta como um desenvolvimento crítico, mas ainda assim um desenvolvimento, de uma psicanálise constituída como disciplina e prática por outro autor, Freud.

No entanto, as diferenças aqui são muito mais extensas, envolvendo aspectos relacionados com o entendimento do psiquismo e da consciência e relacionamentos entre estes, assim como considerações metodológicas. De uma forma muito sintética, há um desacordo fundamental quanto à metapsicologia freudiana, e há ainda um desacordo fundamental quanto à forma de abordagem, de tendências abstratas e taxonômicas, mecanicistas ou, ao menos, biologistas, praticada pela psicanálise freudiana. Por isso, é com alguma razão que se pode dizer que Sartre é um continuador de Husserl, ainda que Ihe endereçando algumas críticas, não se podendo dizer o mesmo em relação a Freud. De fato, na melhor das hipóteses, é legítimo afirmar que Sartre é um crítico de Freud, ainda que se disponha a se inspirar na psicanálise. Mas é importante avaliar mais cuidadosamente a posição de Sartre, enquanto representante da fenomenologia que, ao mesmo tempo, se apresenta como proponente de uma psicanálise existencial.

A apreciação crítica que, por regra, os fenomenólogos fazem da psicanálise clássica freudiana dirige-se sobretudo à sua pressuposição de uma base pulsional de carácter biológico. A esta tendência naturalizante, que faria radicar ultimamente o psiquismo numa dimensão fisiológica, oporiam os fenomenólogos, como uma resistência bem característica das humanidades, uma dimensão de significação dos fenômenos psíquicos. O problema não reside, contudo, numa falta de atenção da psicanálise relativamente a esta dimensão significativa. Pelo contrário, é manifesta e reconhecida a relevância que para a psicanálise e para Freud dispõem as representações e a interpretação das suas significações. 0 extraordinário impacto da psicanálise nas ciências humanas e nas humanidades em geral deve-se muito a esta onipresença, depois de Freud, da significação na consideração da vida psíquica. O problema estaria, portanto, não aí, mas na incompatibilidade entre esta dimensão de significações e, depois, a outra, simplesmente natural, biológica, fisiológica, de que realmente Freud jamais abdica. É neste sentido que Sartre identifica uma contradição profunda na psicanálise, ao estabelecer ao mesmo tempo um elo explicativo e compreensivo nos fenômenos que estuda (SARTRE, 2007). A fenomenologia, pelo menos numa primeira abordagem, tende a reagir mal a uma apresentação que mistura tanto a dimensão fisiológica com a significativa, quanto as dimensões explicativa e compreensiva, esforçando-se por dar conta de uma incompatibilidade de princípio entre estas. Pressente-se aqui todo o debate entre fato natural e 
humanidade, explicação e compreensão, causalidade e sentido, ciências do natural e ciências do humano.

Em meio a reflexões como estas torna-se claro que a base da psicanálise existencial não se apresenta independente da psicologia fenomenológica, do mesmo modo em que fica compreensível a crítica de Sartre a Freud através de Husserl. Pois, o método sartriano, pensado na esteira próxima de Husserl e em vista da constituição de uma ciência, não é dispensado com a proposta de uma psicanálise existencial. Contudo, é evidente que o acento deixa de ser colocado na pretensão de constituição de uma ciência, tornando-se bem menor a subordinação, por assim dizer, ao espírito disciplinar que Husserl perseguia. Mas se quisermos pensar ainda o que de fato diferencia a psicologia fenomenológica sartriana de sua psicanálise existencial para além de Husserl e Freud, devemos ressaltar a forte influência de outros dois autores no desevolvimento desta última. Isto é, uma das maneiras por que podemos distinguir a psicanálise existencial da psicologia fenomenológica sartriana está na menor presença de Husserl, compensada por uma maior presença de Heidegger em $O$ Ser e o Nada, assim como na maior presença de Marx em Questões de Método.

A psicanálise existencial se revela assim como um método pensado a partir de inúmeros diálogos, críticas, inspirações e contraposições com a teoria destes autores principais. Este esforço de Sartre em desenvolver um método que de fato possibilitasse a compreensão do homem como liberdade em situação, sem reduzí-lo a determinismos, é sua maior contribuição às ciências humanas e a todos aqueles que buscam realizar um estudo compreensivo de uma vida particular. Além disso, o filósofo não se restringe somente ao âmbito da produção teórica, mas mostra a aplicabilidade de seu método de psicanálise na produção de biografias. Isto é, Sartre põe em prática sua psicanálise existencial por meio do que se costuma chamar de "analisandos de papel", célebres personalidades analisadas pelo método sartriano como Baudelaire, Mallarmé, Genet e Flaubert, de forma a corroborar com o desejo do autor de não permanecer restrito a uma filosofia contemplativa, mas desenvolver um método que possibilitasse uma prática.

Deste modo, é em $O$ Ser e o Nada, em meio às influências já citadas, que Sartre (2001) desenvolve seu método a fim de encontrar fundamentos para algo que fosse além de uma simples descrição das estruturas do Para-si, modo de ser da realidade humana. O autor parece realizar um verdadeiro passeio que vai do ontológico ao empírico e que redunda, então, em sua possível psicanálise. Ao longo do capítulo de Psicanálise Existencial de O Ser e o Nada, Sartre faz diversas referências a tal urgência metodológica, urgência esta que revela sua necessidade de pensar outro caminho, que ultrapassasse alguns problemas deixados por Freud. Suas indagações o levam a 
afirmar que uma investigação da realidade humana só poderia ser levada adiante se conduzida de acordo com um método específico; e esta é, por fim, a motivação primordial de sua psicanálise existencial (SARTRE, 2001).

As questões de Sartre com a metodologia provêm de seus estudos sobre psicologia e, principalmente, sobre a teoria freudiana, com a qual mantinha constante "diálogo" intelectual. Segundo Cannon (1993), a posição adotada pelo existencialista é "por e contra Freud" (p. 16), pois, é na psicanálise que ele encontra inspiração para pensar sua proposta, ao mesmo tempo em que se torna um de seus grandes críticos, reformulando noções centrais deste pensamento.

Uma das principais divergências entre Sartre e Freud refere-se ao fato de que a psicanálise empírica freudiana define o homem por seus desejos. Para Sartre (2001), o psicólogo que parte deste pressuposto "permanece vítima da ilusão substancialista" (p.682) entendendo o desejo como um "conteúdo" da consciência, existente no homem. Para a psicanálise existencial, essa questão foi superada pela fenomenologia, a qual estabelece desde o início que se todo desejo é desejo de um desejado, ou, em outras palavras, se desejo um copo d'água ou um corpo de mulher não posso, de modo algum, considerar que esse copo ou esse corpo residem em meu desejo, posto que para Sartre todo e qualquer objeto desejado está fora, é objeto transcendente para a consciência desejante.

Ainda neste caminho, Sartre (2001) alerta para outro erro comum na investigação psicológica, que consiste em reduzir o homem a uma combinação de esquemas abstratos e universais considerando essa generalização um fato irredutível, expressão máxima do espírito de análise. Ele exemplifica tal questão através de uma descrição de Paul Bourget a respeito de Flaubert que se sustenta no dado genérico, como por exemplo, uma "ambição desmedida" para justificar e traçar uma suposta "psicologia" do escritor francês. Para Sartre, tal explicação de Bourget é vaga, pois apenas exprime o que considera como "corpos simples da psicologia", isto é, determinações abstratas que tanto poderiam ser estas como quaisquer outras, que não possuem relações internas entre si já que não alcançam o verdadeiro irredutível da vivência em questão. Em resumo, a crítica sartriana indica que este tipo de análise não nos leva a outro lugar que não o das generalizações abstratas, das afirmações soltas, como dizer simplesmente que Flaubert era "alto e ruivo" (SARTRE, 2001). É nesse sentido que se constrói sua proposta; a de chegar a um verdadeiro irredutível, um irredutível que nos satisfaça e que não renegue o dado individual e concreto, mas que vá além da simples associação de abstrações combinadas e agrupadas por determinismos causais.

Como via de acesso a uma compreensão satisfatória do homem, Sartre propõe a noção de projeto fundamental. Ele parte da idéia de 
que a pessoa é uma totalidade e que cada uma de suas escolhas, das menores as mais significativas, devem ser consideradas como expressão integral da pessoa em questão, expressando sempre e necessariamente um sentido transcendente. A psicanálise existencial pretende, então, compreender o projeto fundamental do homem, realizando uma comparação entre suas escolhas de modo a destacar o fio condutor que as unifica, já que "em cada uma delas acha-se a pessoa em sua inteireza" (SARTRE, 2001, p. 690).

O trilho a percorrer na psicanálise existencial deve, então, ser um trilho de escolhas, em que a significação de cada uma delas deve ser encontrada em outras escolhas mais originárias. A presunção da proposta sartriana é de que as escolhas estejam concatenadas numa rede de reenvios de sentido, cabendo ao trabalho de análise fazer esse percurso de modo a destacar tal sentido que as unifica. Desta forma, a ambição sartriana de colocar em discussão a possibilidade de uma psicanalise existencial se sustenta para além de uma simples descrição empírica. O que o filósofo pretende é gerar um método de decifração e elucidação das vivências, tal como o de Freud e, para isso, como afirma o próprio Sartre (2001), "convém sublinhar [...] em que medida a psicanalise existencial irá inspirar-se na psicanálise propriamente dita, e em que medida irá diferir radicalmente" (p.696). Os pontos de aproximação elencados por Sartre dizem respeito ao fato de que ambas as psicanálises tomam o homem como uma "historização perpétua", sendo inconcebível considerá-lo apartado de sua situação. Além disso, ambos concordam que a própria pessoa não se encontra em uma posição favorável para se autoanalisar sendo a relação de alteridade promotora de novas perspectivas e ,por esse motivo, frutífera para quem deseja se conhecer. Também ambos consideram que todo ato é simbólico, porém, na psicanálise proposta por Sartre se faz importante manter essa simbólica sempre aberta e flexível no intuito de não impregnar a percepção do analista com a rigidez e a "poeira" da teoria que embaçam o seu olhar, recaindo em uma descrição pautada em dados abstratos e genéricos. Para Sartre, esse é um dos principais "erros" de Freud, o de ter estabelecido além de uma simbólica rígida, um irredutível substancial também a priori, a saber, a libido, contaminando assim toda a rica leitura simbólica pelo viciado ângulo de interpretações semi-prontas que partem sempre de um mesmo cenário de sentidos.

No entanto, a diferença mais radical entre os dois autores reside na incompatibilidade em relação ao ponto chave de toda edificação teórica da psicanálise freudiana, o inconsciente. Para Sartre, somos sempre consciência mas nem sempre conhecimento, o que não significa, de modo algum, considerar que haja uma instância inconsciente. Essa discordância fundamental acontece como um desdobramento coerente e derivado de toda a ontologia estabelecida desde a introdução de O Ser e o Nada. Uma vez que Sartre vê a 
realidade humana como liberdade, uma liberdade que implica em abertura para os seus possíveis e por isso se faz comprometida e engajada com sua situação, considerar a possibilidade de uma instância inconsciente seria como que permitir ao homem uma eterna desculpa, ou seja, uma eterna possibilidade de não assumir sua própria angústia e inconsistência que são caracteristicas de seu modo de ser.

Além disso, a noção de inconsciente provoca uma cisão entre instâncias conscientes e inconscientes que co-pertecem a uma mesma interioridade psíquica. Tanto a concepção de uma interioridade psíquica quanto a ideia de uma possível cisão em instâncias que formariam ainda um "aparelho", não se encaixam nas bases fenomenológicas de Sartre. Através da própria fenomenologia e sua primazia da intencionalidade, além do auxílio de Heidegger para se pensar nosso modo de existir como "diaspórico", isto é, perpétua fuga de si, tais ideias que nos remetem a um sujeito interiorizado aos moldes de Descartes não se sustentam. Sendo assim, não poderíamos, através da psicanálise existencial, buscar um "lá dentro", um "por detrás", que precisa ser investigado e desvelado, posto que, ao tomarmos o homem enquanto consciência "de ponta a ponta" devemos considerar que tudo está em ato, num só golpe, claro como uma ventania (SARTRE, 2005a).

Em linhas gerais estes são os pontos principais elencados por Sartre em sua primeira elaboração da psicanálise existencial em $\mathrm{O}$ Ser e o Nada. Contudo, há um segundo momento de desenvolvimento de seu método no qual ele introduz ao seu pensamento alguns elementos do marxismo. A influência do marxismo, crescente a partir dos anos 50, levou Sartre a evitar um tipo de discurso excessivamente centrado na consciência e na existência individual e que Ihe merecera, aliás, críticas da parte de intelectuais comunistas - como Lukács (1973) e também Marcuse (1948). Censuravam-lhe o pensamento por ser uma espécie de "filosofia burguesa", ainda que com um certo aspecto radical que poderia entusiasmar os menos prevenidos.

Em Questões de Método, texto introdutório da Crítica da Razão Dialética, encontramos o desenvolvimento da psicanálise existencial em novos contornos. Sartre (1987) se mostra, neste trabalho, empenhado em "constituir uma antropologia estrutural e histórica" (p.111), a partir de uma interlocução, desta vez, com Marx, tendo em vista uma compreensão de homem que não o dissolvesse "em ácido sulfúrico", como faziam, segundo ele, certas vertentes do materialismo dialético. Apesar das mudanças de perspectivas, seus objetivos se situam dentro de uma intenção que ainda permanece viva, a de não sucumbir em abstrações, conforme podemos identificar em sua crítica ao marxistas: 
Pensar, para a maioria dos marxistas atuais, é pretender totalizar e sob, este pretexto, substituir a particularidade por um universal; é pretender conduzir-nos ao concreto e apresentar, sob este título, determinações fundamentais mas abstratas (SARTRE, 1987, p.133)

Nesta obra, Sartre prossegue em uma discussão crítica sobre a tendência do marxismo de dissolver o particular no universal, reivindicando que devemos entender o homem como aquele que é ao mesmo tempo o produto de seu próprio produto e um "agente histórico que não pode, em caso algum, passar por um produto" (SARTRE, 1987, p.150). O único recurso possível para tal compreensão de homem é entendê-lo como um projeto que interioriza a exterioridade e exterioriza a interioridade, isto é, processo dialético de superação da realidade dada rumo a um campo de possíveis. É célebre a afirmação que Sartre aí faz neste sentido: "Para nós, o homem caracteriza-se, antes de tudo, pela superação de uma situação, por aquilo que consegue fazer do que foi feito dele, embora nunca se reconheça na sua objetivação" (SARTRE, 1987, p. 151-152). Este será o limite que imunizará Sartre perante o contágio do anti-historicismo e da morte do sujeito que varrerá a França, sobretudo nos anos 70, anos finais de sua vida.

As ideias sartrianas de inspiração marxista refletem assim os pontos principais responsáveis pela reformulação e enriquecimento de seu método de psicanálise existencial. Esta nova etapa é também marcada pela introdução, em Questões de Método, do método progressivo-regressivo de Henri Lefebvre como via de investigação de uma vida particular, método que passa a ser usado a partir de então nos trabalhos biográficos, cujo exemplo mais expressivo encontra-se em O idiota da família (SARTRE, 1988).

Diante de todo o caminho percorrido até aqui, podemos observar com clareza as contribuições de Sartre à psicologia. Desde sua psicologia fenomenológica ao seu método de psicanálise existencial, o filósofo nos oferece novas bases de pensamento para o estudo do homem que possibilitam uma compreensão, ao mesmo tempo, de sua historicidade e de sua singularidade. De fato, esta grande contribuição nos aponta um caminho, mas o desenvolvimento de tais questões no âmbito de uma prática clínica não faz parte, a nosso ver, do legado sartriano. Como vimos, Sartre tinha como objetivo de sua psicanálise o estudo de seus "analisandos de papel", mas as implicações de sua psicologia e psicanálise para a clínica hoje é ainda uma tarefa que nos propomos a pensar.

\section{Para uma clínica de inspiração sartriana}

Não é verdade que possamos afirmar confortavelmente que Sartre tenha formulado os princípios para uma prática clínica baseada na 
sua filosofia e na sua psicologia. Se é legítimo fazer-se menção seja a uma filosofia sartriana seja a uma psicologia sartriana, ambas originais, não se justifica, porém, falar de uma clínica sartriana. Isto não impede, bem entendido, que se pense uma prática clínica inspirada em Sartre. Como se sabe, em O Ser e o Nada, Sartre ia deixando o aviso de que ainda faltava à psicanálise existencial o seu Freud.

Quando Sartre afirma faltar à psicanálise existencial o seu Freud cremos estar assumindo, de uma forma clara e razoável, faltar à psicanálise existencial a sua clínica. Neste ponto divergimos daqueles que, um pouco apressadamente, juntam a uma filosofia e a uma psicologia sartrianas, uma clínica de Sartre. Apesar destas ressalvas, já na obra de 1943, Sartre deixa nitidamente indicada uma pretensão de que uma clínica viesse a constituir-se, sobretudo pela referência explícita que ele faz à relação clínica, chegando a apontar algumas nuances fundamentais de como deveria ser uma atitude de um psicanalista existencial em oposição a atitude de um psicanalista de base freudiana.

Dispostos os dados assim, cabe dar conta da existência de importantes elementos no pensamento de Sartre que constituem contributos para inspirar uma prática. Em outras palavras, quando se trata de pensar na clínica com base em Sartre, devemos adentrar na criação de algo novo, que não foi desenvolvido pelo autor, e que nos joga no terreno vivo da experiência, mas precisamente a partir do quadro de referências constituídos no seio da sua psicologia fenomenológica e da sua psicanálise existencial.

Tal quadro confronta-nos prontamente com a afirmação sartriana de que a introdução de um apriorismo no relacionamento conduz a uma inapelável suspensão da própria relacionalidade. Do mesmo modo que a existência precede a essência, considerada a pessoa na sua individualidade, podemos também afirmar que o encontro concreto na relação precede qualquer esquema que a procurasse caracterizar em abstrato. Isto quer dizer, em primeiro lugar, que devemos partir do próprio terreno vivo da experiência e da relação intersubjetividade.

Há no espaço clínico o acontecimento de uma relação entre duas pessoas que se predispõem a uma situação clínica. Assim sendo, quais são as condições desta situação? Como afirma Renato Mezan (2002), a demanda de quem procura ajuda, independente da metodologia clínica, é quase sempre a mesma: "sofrer menos, viver melhor, compreender algo de si e da forma como se relaciona com os demais" (p.40). Portanto, ocorre assim, alguém que procura por um serviço de ajuda e paga por ele. Por um viés objetivo, podemos destacar que há um espaço e um tempo que constituem uma sessão, e esta desde o início já contém as finalidades desejadas, conforme apontamos, para aquele espaço, sem que sejam revelados, no 
entanto, explicitamente, os meios para tal. A preocupação com os meios é justamente uma questão de método, o que será fundamentalmente o marco divisor de águas das diferentes abordagens teóricas em psicologia clínica.

De recorte fenomenológico, a clínica de inspiração sartriana doará ao fenômeno da compreensão o papel principal, reivindicando com isso uma constante necessidade de se pensar na atitude daquele que compreende, como uma atitude fenomenológica. A nosso ver, somente esta postura diante do fenômeno faz com que ele revele seu sentido criado a partir da relação que se dá naquele espaço, não procurando sentidos prontos que seriam constituídos aprioristicamente.

Assim, o objetivo da clínica será permitir que este espaço seja aberto à aparição do ato de criação dos sentidos, ao invés de uma busca por verdades independentes da relação que ali está em jogo. A possibilidade de criação dos sentidos, nesse caso, é uma possibilidade aberta pela relação intersubjetiva que se estabelece entre dois parasis sob o modo de ser para-outrem. Ambos, analista e analisando desfrutam nesse caso do olhar do outro como objetivação necessária para a compreensão do fenômeno por um "lado de fora", e não simplesmente na "luz que ilumina sem relevos" da subjetividade (SARTRE, 2001). Desta maneira, ambos possibilitam a aparição de uma construção de sentidos conjunta, através de uma relação de confiança que se sustenta no ponto de vista de outrem, de um outro perfil, do mesmo fenômeno.

Apesar deste trabalho intersubjetivo conjunto, devemos destacar que ambos envolvidos na relação para-outrem da clínica não ocupam lugares semelhantes nessa situação. Pois, enquanto o analista ocupa seu lugar justamente de analista, o analisando busca encontrar algo de si naquele espaço, o qual de alguma forma indica ser o tempo da sessão pertencente às suas questões pessoais. Deste modo, estes lugares definidos constituem uma característica inerente à situação clínica que provocará, por sua vez, a maneira pela qual será estabelecida tal relação. Isto é, cabe ao analista então uma disponibilidade de abertura para receber aquilo que o outro traz, para ouvir de maneira ampla, sem que isso, no entanto, caracterize uma passividade ou uma ausência impossível de sua própria subjetividade. O que devemos é pensar novamente em uma abertura de atitude, que interrogue os sentidos prontos ou feitos, e que leva em conta uma postura não-judicativa em relação aquilo que aparece, ao mesmo tempo legitimando como dado real as próprias vivências do analista como parte integrante da constituição dos sentidos.

Uma clínica de inspiração sartriana se caracteriza por uma busca conjunta de se construir novos ângulos de visão sobre as diferentes perspectivas já constituídas. Uma atitude fenomenológica implica em tomar o outro enquanto fenômeno que se manifesta através dessas 
diferentes perspectivas. Esse outro "multifacetado" se revela pela história de vida familiar que narra, pelas circunstâncias atuais de seu horizonte existencial, pela maneira e tom através dos quais comunica as suas questões, pela forma como se veste, pela maneira que se senta, por aquilo que escolhe dizer, inclusive pelas próprias escolhas de má-fé que realiza. Todo esse mosaico de facetas significa a expressão do projeto que faz de si, e nenhum desses ângulos é "falso", nem mesmo as mentiras e omissões.

Se, de fato, podemos pensar assim, consideramos que o objetivo do trabalho clínico é permitir à pessoa a possibilidade de que ela mesma possa vir a reconhecer-se. Como afirma Sartre, o olhar do outro permite o reconhecimento de minha condição existencial, já que através dele me é dado um "lado de fora", isto é, um ângulo meu, que seria impossível de atingir sozinho. Para me reconhecer como tal, necessito deste outro que me olha. Desta forma, diz Paulo Perdigão (1995), "só estou capacitado a formular um juízo objetivo, saber-me de determinado modo [...] porque esse tipo de autoconhecimento passa pelo Outro" (p. 143). Tal condição de me reconhecer diante deste outro que me olha é belamente expressa por Sartre na carta que Daniel escreve a Mathieu no romance Sursis:

\begin{abstract}
Durante um instante, foste o mediador entre mim e mim mesmo, o mais precioso do mundo aos meus olhos, pois esse sólido e denso que eu era, que queria ser, tu o percebias tão simplesmente, tão vulgarmente, como eu te percebia. [...] Compreendi, então, que a gente só se podia alcançar através do juízo de outrem [...] Que angustia descobrir subitamente esses olhos como um ambiente universal do qual não posso fugir [...] Transformo para uso próprio, e com toda a tua indignação, a palavra imbecil e criminosa de vosso profeta, esse 'penso, logo existo' que tanto me fez sofrer - pois quanto mais eu pensava menos me parecia existir - e digo: vêem-me, logo existo (SARTRE, 2005b, p.398).
\end{abstract}

Tal parodia sartriana do cogito, "vêem-me, logo existo", exprime essa fundamental condição que nos liga irremediavelmente ao outro, principalmente se pretendemos alcançar uma compreensão a respeito de nós mesmos. O homem de Sartre, "mistério em plena luz", carece dos meios necessários para se alcançar, posto que desfruta de tudo ao mesmo tempo "sem sombra, sem relevo, sem relação de grandeza; não por que essas sombras, valores e relevos existam em alguma parte e lhe estejam ocultos, mas sobretudo porque concerne a uma outra atitude humana estabelecê-los" (SARTRE, 2001, p. 698). Ainda se faz pertinente pontuar que, apesar da relação ser necessária ao reconhecimento, o maior intuito de uma clínica de inspiração sartriana, segundo nosso entendimento, deve ser a criação da possibilidade de que a própria pessoa consiga se reconhecer na sua angustiante liberdade. Reconhecer designa: conhecer de novo, 
conhecer o que já compreende, distinguir, admitir, autenticar, endossar, declarar-se, confessar-se, assumir-se, conciliar-se. O que pretendemos é justamente como diz Sartre: "reivindicar como decisiva a intuição final do sujeito" (2001, p.702), ou em outras palavras, esperamos que o outro seja capaz de se identificar como abertura, de admitir sua incompletude, de endossar seu modo de ser escolhido, em suma de assumir-se como liberdade por se fazer.

O fato de podermos identificar no rastro da obra de nosso autor um "caminho a seguir" em vista de uma clínica psicológica de recorte sartriano, não suprime, a nosso ver, as dificuldades teóricas e metodológicas a serem enfrentadas. Por este motivo, buscamos demarcar, no presente artigo, o âmbito preciso em que se constituem três campos distintos de consideração do pensamento de Sartre para o universo da psicologia. Em primeiro lugar, o campo de uma psicologia fenomenológica sartriana, particularmente aprofundado na fase inicial de suas investigações fenomenológicas e que lança a base para seus percursos futuros. Em segundo lugar, o campo de uma proposta de psicanálise existencial como alternativa e resposta ao método freudiano. Por fim, o campo de uma clínica inspirada no pensamento de Sartre, que, como procuramos mostrar, proporciona a possibilidade de adentrarmos na criação de algo novo, que não foi desenvolvido diretamente pelo autor, mas que nos joga no terreno vivo da experiência heurística, no balanço entre a descoberta e a invenção.

\section{Referências}

CANNON, B. Sartre \& psychoanalysis: an existentialist challenge to clinical metatheory. Lawrence: University Press of Kansas, 1991.

HUSSERL, E. Article pour l'encyclopédie britannica, trad. fr. par $P$. Cabestan, N. Depraz et A. Mazzú, revue par F. Dastur in Psychologie phénoménologique. Paris: Vrin, 2001.

LAPLANCHE, J.; PONTALIS, J. Vocabulário de Psicanálise. São Paulo: Martins Fontes, 1992.

LUKÁCS, G. Existentialism In: Marxism and human liberation: Essays on History, Culture and Revolution by Georg Lukács. New York: Dell Publishing Co., 1973.

MARCUSE, H. Existentialism: Remarks on Jean-Paul Sartre's L'Être et le néant In. Philosophy and phenomenological research, Vol. VIII, n. ${ }^{3}$ 3, 1948

MEZAN, R. A vingança da esfinge. São Paulo: Casa do Psicólogo, 2002.

PERDIGÃO, P. Existência e liberdade - uma introdução à filosofia de Sartre. Porto Alegre: L\&PM, 1995. 
SARTRE, J.P. Questão de Método. In. Sartre (Os Pensadores). São Paulo: Nova Cultural, 1987.

L'idiot de la famille: Gustave Flaubert de 1821 à 1857. Paris: Gallimard, 1988.

A transcendência do ego: esboço de uma descrição fenomenológica. Lisboa: Colibri, 1994.

- O imaginário: psicologia fenomenológica da imaginação. São Paulo: Ática, 1996.

O ser e o nada: ensaio de ontologia fenomenológica.

Petrópolis: Vozes, 2001.

2005a.

. Situações I: criticas literárias. São Paulo: Cosac Naify,

. Sursis. Rio de Janeiro: Nova Fronteira, 2005b.

L\&PM, 2007

Esboço para uma teoria das emoções. Porto Alegre:

. A imaginação. Porto Alegre: L\&PM, 2008.

Endereço para correspondência

André Barata Nascimento

Departamento de Comunicação e Artes - Universidade da Beira Interior - UBI Covilhã, Lisboa, Portugal

Endereço: Alameda Dom Afonso Henriques, 62, 4. ${ }^{\circ}$ Esq. 1900-183 Lisboa

Telefone: (351) 9634533

email: abarata@ubi.pt

Carolina Mendes Campos

Pontifícia Universidade Católica do Rio de Janeiro - PUC-Rio, Rio de Janeiro, Rio de Janeiro, Brasil

Endereço: José Roberto Macedo Soares n. 12/102, Gávea cep: 22470-100

Telefone: (21) 2521-7641

Email: carolinamendescampos@gmail.com

Fernanda Alt

Universidade do Estado do Rio de Janeiro - UERJ - Rio de Janeiro, Rio de Janeiro, Brasil

Endereço: José Roberto Macedo Soares n. 12/102, Gávea cep: 22470-100

Telefone: (21) 2521-7641

Email: fernandaalt@gmail.com

Recebido em: 31/05/2012.

Reformulado em: 30/11/2012.

Aceito para publicação em: 30/11/2012.

Acompanhamento do processo editorial: Ana Maria Lopez Calvo de Feijoo

\section{Notas}

*Filósofo, Professor Doutor em Filosofia pela Universidade de Lisboa, Portugal

**Psicóloga Doutoranda em Psicologia Clínica pela Pontifícia Universidade Católica do Rio de Janeiro- PUC-Rio

***Psicóloga, Doutoranda em Filosofia pela Universidade do Estado do Rio de Janeiro - UERJ 